\title{
Azole-resistant Aspergillus fumigatus in the environment of northern Italy, May 2011 to June 2012
}

A Prigitano ${ }^{1}$, V Venier ${ }^{1}$, M Cogliati $^{1}$, G De Lorenzis² ${ }^{2}$ M C Esposto ${ }^{1}$, A M Tortorano (annamaria.tortorano@unimi.it) ${ }^{1}$

1. Dipartimento di Scienze Biomediche per la Salute, Università degli Studi di Milano, Milano, Italy

2. Dipartimento di Scienze Agrarie e Ambientali, Universita`degli Studi di Milano, Milano, Italy

Prigitano A, Venier V, Cogliati M, De Lorenzis G, Esposto MC, Tortorano AM. Azole-resistant Aspergillus fumigatus in the environment of northern Italy, May 2011 to June 2012. Euro Surveill. 2014;19(12):pii=20747. Available online: http://www.eurosurveillance.org/ViewArticle.aspx?Articleld=20747

In recent years acquired azole resistance in Aspergillus fumigatus has been increasingly reported and a dominant mechanism of resistance $\left(\mathrm{TR}_{34} / \mathrm{Lg8H}\right)$ was found in clinical and environmental isolates. The aim of the present study was to investigate the prevalence of azole resistance in environmental $A$. fumigatus isolates collected in northern Italy. A. fumigatus grew from 29 of 47 soil samples analysed. Azole-resistant isolates were detected in $13 \%(6 / 47)$ of the soil samples and in $21 \%(6 / 29)$ of the soil samples containing A. fumigatus. High minimal inhibitory concentrations (MIC) of itraconazole ( $\geq 16 \mathrm{mg} / \mathrm{L}$ ) and posaconazole $(\geq 0.5 \mathrm{mg} / \mathrm{L}$ ) were displayed by nine isolates from six different soil samples, namely apple orchard (1 sample), rose pot compost (2 samples), and cucurbit yields ( 3 samples). Seven isolates had a MIC $=2 \mathrm{mg} / \mathrm{L}$ of voriconazole. Seven of nine itraconazole and posaconazole resistant isolates harboured the same $\mathrm{TR}_{34} / \mathrm{Lg8H}$ mutation of $\operatorname{cyp}_{51 A}$. These findings, together with the occurrence of resistant clinical isolates, suggest that azole resistance should be considered in primary patient care.

\section{Introduction}

Aspergillus fumigatus is a filamentous fungus that causes a broad spectrum of diseases. Invasive lifethreatening infection affects subjects with compromised immune system, mainly patients with haematological malignancies, recipients of haematopoietic stem cells or solid organ transplantation, or patients under prolonged treatment with steroids. Chronic aspergillosis occurs in patients with pre-existing pulmonary or sinus disease, and locally invasive infection occurs as a result of trauma or surgery.

A. fumigatus is ubiquitous in the soil and in decaying organic matter, and produces asexual spores (conidia) that are continuously dispersed in the air. Most of the patients develop aspergillosis following inhalation of conidia into the alveoli or the upper airways. Triazole antifungals, itraconazole, posaconazole and voriconazole, are increasingly used in the treatment and prophylaxis of aspergillosis [1]. Voriconazole is recommended as first line treatment for invasive aspergillosis in European and American guidelines [2-5].

A. fumigatus is generally susceptible to these antifungals. However, in the recent years, azole resistance has been increasingly reported in patients under long-term antifungal treatment and also in azole naïve patients as well as in strains from the environment [1,6-8].

The most common mechanism of azole resistance is an alteration of lanosterol 14-a-demethylase, the key enzyme in the biosynthetic pathway of the ergosterol, a main component of the cell membrane. Different point mutations in the $c y p 51 A$ gene, which encodes this enzyme, have been shown to confer resistance [1,9-11]. A dominant mechanism of resistance involving a 34-bp tandem repeat in the gene promoter region and a substitution of a leucine for a histidine at codon 98 (TR34/ L98H) was initially found in clinical and environmental isolates from the Netherlands and a correlation to the use of azoles in the environment was suggested [12].

During the international surveillance of azole resistance in $A$. fumigatus clinical isolates (SCARE Network) intrinsic resistance was observed in four of 209 isolates collected in Italy [13] and the TR34/L98H mutation was detected in all these isolates. The aim of the present study was to investigate the prevalence of azole resistance in $A$. fumigatus environmental isolates collected in northern Italy.

\section{Methods}

Environmental sampling was carried out in northern Italy in the period between May 2011 and June 2012. A total of 47 soil samples, namely 12 samples from apple orchard, 12 from cucurbit fields, six from vineyards, five from cereals fields, five from pot composts (including rose and other flower pot compost), three from flowerbeds of public gardens, three from hospital gardens, and one from compost purchased from a commercial garden centre, were examined. The sampling sites are reported in the map (Figure 1). Azole fungicides are 


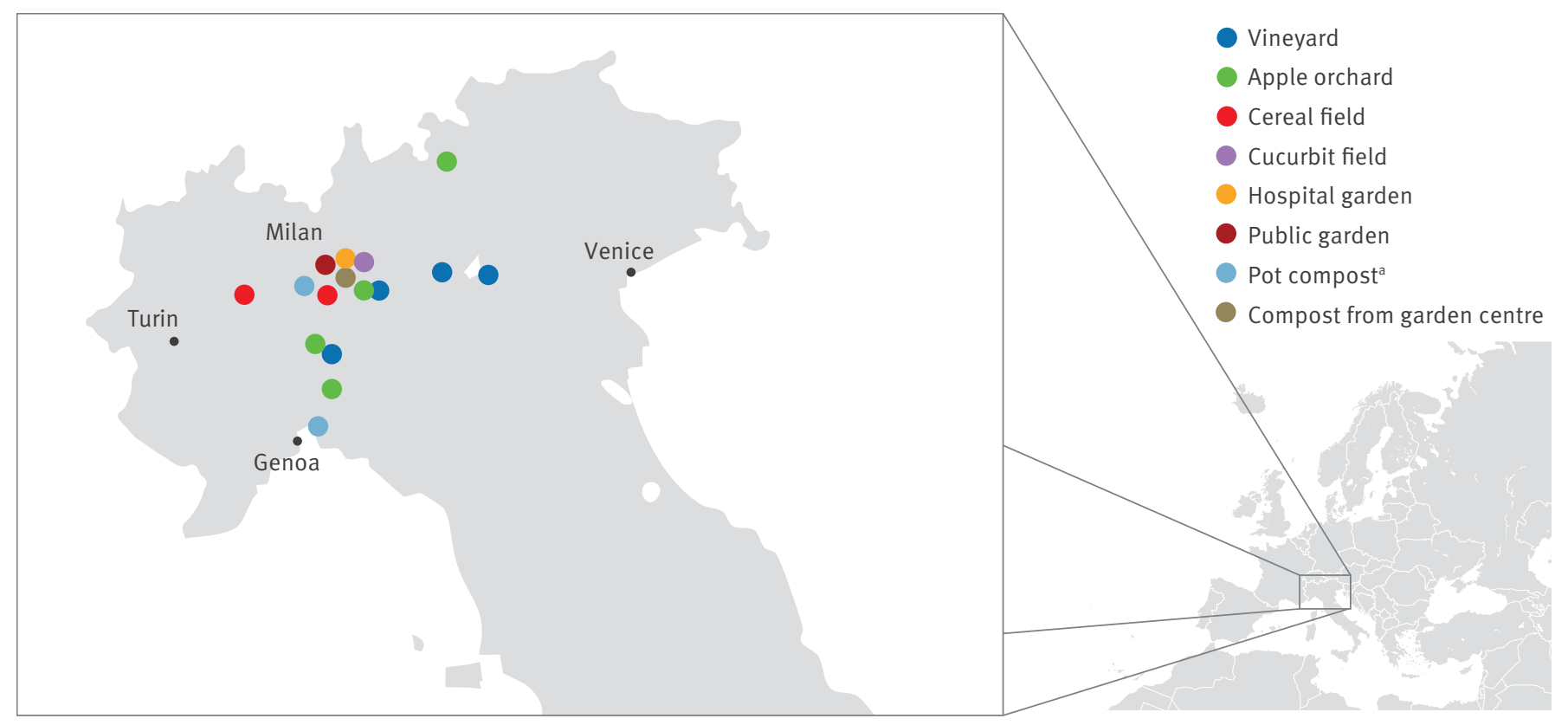

Only sites where more than one sample could be analysed, are shown.

a Including rose and other flower pot compost.

used in all the sampled environments, except gardens. No information was available for composts.

The samples were treated according to the method previously described by Snelders et al. [12] with minor modifications. Briefly, $2 \mathrm{~g}$ of each sample were suspended in $8 \mathrm{~mL}$ of sterile distilled water added of $1 \%$ Tween 20 (Sigma, St. Louis USA) and chloramphenicol (0.5 g/L, Sigma) and vortexed. The suspension was stored at room temperature for 30 to $60 \mathrm{~min}$ and 100 $\mu \mathrm{L}$ of the supernatant was inoculated on two plates of Sabouraud dextrose agar (SDA, Biolife, Milan, Italy) supplemented with chloramphenicol (0.5 g/L) and on two plates of SDA supplemented with chloramphenicol and itraconazole ( $4 \mathrm{mg} / \mathrm{L}$, Janssen, Beerse, Belgium). Control plates and itraconazole-containing plates were incubated at $37^{\circ} \mathrm{C}$ and at $42^{\circ} \mathrm{C}$ (to limit the fungal growth) and examined after 24,48 , and 72 hours of incubation. All the $A$. fumigatus isolates grown on itraconazole-containing agar and an equal number of isolates grown on control plates were selected and maintained on SDA medium.

The isolates were identified by macroscopic and microscopic morphology on Czapek agar medium (Difco, Becton Dickinson, Buccinasco, Italy) as A. fumigatus species complex.
A. fumigatus isolates grown in presence of itraconazole and an equal number of isolates grown on control plates were tested for antifungal susceptibility to itraconazole, posaconazole and voriconazole. Susceptibility testing was performed, within one month from the isolation, by broth microdilution method according to European Committee on Antimicrobial Susceptibility Testing (EUCAST) methodology [14]. The minimal inhibitory concentration (MIC) of all the azoles was determined visually as the lowest concentration of drug giving a complete inhibition of fungal growth. All tests were performed in duplicate. Candida parapsilosis ATCC 22019 and C. krusei ATCC 6258 were included as quality control in each test.

Susceptibility testing was also performed using Etest strips (BioMérieux, Bagno a Ripoli, Italy) on RPMI 1640 agar supplemented with $2 \%$ glucose, according to the manufactory indications. Isolates with MIC of itraconazole and voriconazole $>2 \mathrm{mg} / \mathrm{L}$ and those with MIC of posaconazole $>0.25 \mathrm{mg} / \mathrm{L}$ were considered resistant, according to the EUCAST breakpoints [15-17].

Genomic DNA was extracted from the nine azole-resistant and four susceptible isolates using the PrepMan Ultra sample preparation reagent (Applied Biosystems, Foster City, CA). Identification of the isolates as $A$. fumigatus in sensu stricto was confirmed by the amplification and sequencing of a portion of the beta-tubulin 
Environmental origin of itraconazole-resistant Aspergillus fumigatus isolates, Italy, May 2011-June 2012

\begin{tabular}{|c|c|c|c|c|c|c|}
\hline Sample source & Period of sampling & $\begin{array}{l}\text { Examined } \\
\text { samples (n) }\end{array}$ & $\begin{array}{l}\text { Samples with } \\
\text { growth of } A \text {. } \\
\text { fumigatus on } \\
\text { control plates } \\
\text { (n) }\end{array}$ & $\begin{array}{l}\text { Samples with } \\
\text { growth of } A \text {. } \\
\text { fumigatus on } \\
\text { itraconazole } \\
\text { medium (n) }\end{array}$ & $\begin{array}{l}\text { A. fumigatus } \\
\text { isolates on } \\
\text { itraconazole } \\
\text { medium (n) }\end{array}$ & $\begin{array}{l}\text { A. fumigatus } \\
\text { isolates with } \\
\text { confirmed } \\
\text { itraconazole } \\
\text { resistance (n) }\end{array}$ \\
\hline Apple orchard & Oct-Dec 2011 & 12 & 3 & 1 & 1 & $1^{\mathrm{a}}$ \\
\hline Cereal fields & Mar-Apr 2012 & 5 & 5 & 0 & 0 & 0 \\
\hline Compost from garden centre & Apr 2012 & 1 & 0 & 0 & 0 & 0 \\
\hline Cucurbit fields & May and Sep 2011 & 12 & 10 & 8 & 28 & $6^{\mathrm{b}}$ \\
\hline Hospital gardens & Mar-Jun 2012 & 3 & 3 & 0 & 0 & 0 \\
\hline Pot compost & May 2011 & 5 & 5 & 2 & 29 & $2^{c}$ \\
\hline Public gardens & Apr-May 2012 & 3 & 3 & 0 & 0 & 0 \\
\hline Vineyards & Oct 2011 & 6 & 0 & o & 0 & o \\
\hline Total & - & 47 & 29 & 11 & 58 & 9 \\
\hline
\end{tabular}

a The isolate corresponds to one sample collected in the Lombardy region near the northern Italian border.

b The isolates were derived from three samples respectively collected in different fields and/or dates near the city of Milan.

' The isolates were derived from two samples from two different rose pots collected near the city of Genoa.

gene using the primers described elsewhere [9]. The sequences obtained were compared to the sequences present in the GenBank database (www.ncbi.nlm. nih.gov) by basic local alignment search tool (BLAST) analysis and the identification was confirmed if a 99 to $100 \%$ sequence identity was observed.

In addition, two further DNA regions, one inside the $\operatorname{cyp}_{51 \mathrm{~A}}$ gene and one inside its promoter, were sequenced to detect the presence of the point mutation $\mathrm{t} 364 \mathrm{a}$, which leads to the $\mathrm{L} 98 \mathrm{H}$ substitution at the protein level, and the $34^{-b p}$ tandem repeat, both specific for azole resistance. The cyp51A gene fragment (1168 bp) was amplified by polymerase chain reaction (PCR) using the two primers, $\mathrm{P} 450-\mathrm{A}_{1}$ [11] and Cyp51AR2 (5'-AGTGAATAGAGGAGTGAATCC-3'). PCR was performed in a $50-\mathrm{mL}$ volume containing $10 \mathrm{X}$ buffer (10 mM Tris-HCL, pH 8.3; $500 \mathrm{mM} \mathrm{KCl} ; 15 \mathrm{mM} \mathrm{MgCl}_{2}$; Qiagen, Venlo, Netherlands), $1.5 \mathrm{mM} \mathrm{MgCl}_{2}, 200 \mathrm{mM}$ of each of the four deoxynucleotides, $20 \mathrm{pmol}$ of each primer, $2.5 \mathrm{U}$ of Taq polymerase (Qiagen), and $2 \mathrm{~mL}$ of genomic DNA. The thermal cycling profile included an initial step at $94^{\circ} \mathrm{C}$ for $5 \mathrm{~min}, 30$ cycles consisting in denaturation at $94^{\circ} \mathrm{C}$ for $30 \mathrm{~s}$, annealing at $58^{\circ} \mathrm{C}$ for $30 \mathrm{~s}$, and extension at $72^{\circ} \mathrm{C}$ for $1 \mathrm{~min}$, and a final extension at $72^{\circ} \mathrm{C}$ for $5 \mathrm{~min}$. The $P C R$ product was then sequenced using two forward primers, $\mathrm{P}_{450}-\mathrm{A}_{1}$ and Cyp51AF2 (5'-GACATCTCTGCGGCAATGG-3'), and two reverse primers, Cyp51AR2 and Cyp51AR3 (5'-CCATTGCCGCAGAGATGTC-3'), to reach the complete sequencing coverage for both strands of the fragment. The $c{ }_{51} \mathrm{~A}$ gene promoter was amplified and sequenced using the primers $\mathrm{PA}_{5}$ and $\mathrm{PA} 7$ as previously described [10].
All sequences were determined by an ABI PRISM 3100 genetic analyser (Applied Biosystems), electropherograms were analysed by FinchTV software (www.geospiza.com), and sequence alignment was performed using ClustalW algorithm (www.ebi.ac.uk). The cyp51A sequence from $A$. fumigatus strain 237 (GenBank accession number: AF338659) was used as wild type reference.

Azole-resistant as well as five susceptible isolates were genotyped by microsatellite analysis using the primers STRAf3A, STRAf3B, STRAf 3 C, STRAf4A, STRAf4B, and STRAf4C as described elsewhere [18].

\section{Results}

A. fumigatus grew in 29 of 47 soil samples (62\%), mainly form cucurbit and cereal fields and rose pot composts (Table 1). No A. fumigatus was isolated from vineyards and compost from garden centre. A total of 58 isolates grew on itraconazole-containing agar.

Broth microdilution and Etest confirmed itraconazole resistance in nine isolates (MIC $\geq 16 \mathrm{mg} / \mathrm{L}$ ). All these isolates were also posaconazole resistant (MIC $\geq 0.5$ $\mathrm{mg} / \mathrm{L}$ ). Seven isolates showed an intermediate susceptibility to voriconazole ( $\mathrm{MIC}=2 \mathrm{mg} / \mathrm{L}$ ) by broth microdilution method according to EUCAST (Table 2). Etest MIC values were lower but MIC values obtained by broth microdilution and Etest were in the $+/-2$ dilution range. The $A$. fumigatus control isolates were susceptible to itraconazole (range of MICs: 0.06 to $0.12 \mathrm{mg} / \mathrm{L}$ ), posaconazole (range of MICs: $\leq 0.03$ to $0.06 \mathrm{mg} / \mathrm{L}$ ), and voriconazole (range of MICs: 0.06 to $0.25 \mathrm{mg} / \mathrm{L}$ ). Identical results were obtained in tests performed in duplicate. 
TABLE 2

Results of EUCAST and Etest susceptibility testing, and analysis of mutations in cyp51A, Italy, May 2011-June 2012

\begin{tabular}{|c|c|c|c|c|c|c|c|c|}
\hline \multirow{2}{*}{$\begin{array}{l}\text { Isolate } \\
\text { number }\end{array}$} & \multirow{2}{*}{ Sample source } & \multicolumn{3}{|c|}{ MIC (mg/L) determined by EUCAST } & \multicolumn{3}{|c|}{ MIC (mg/L) determined by Etest } & \multirow{2}{*}{ Mutation in cyp51A } \\
\hline & & $\mathrm{ITZ}^{\mathrm{a}}$ & POS $^{\mathrm{a}}$ & $\mathrm{VRC}^{\mathrm{a}}$ & $\mathrm{ITZ}^{\mathrm{a}}$ & POS $^{\mathrm{a}}$ & $\mathrm{VRC}^{\mathrm{a}}$ & \\
\hline $11-0087 \mathrm{~A}$ & Rose pot compost & $>16$ & 1 & 2 & 132 & 1 & 1 & TR34/L98H \\
\hline 11-0088E & Rose pot compost & $>16$ & 2 & 1 & 16 & 0.5 & 1 & None \\
\hline $11-0099 \mathrm{~A}$ & Cucurbit fields & 216 & 2 & 2 & 232 & 1 & 2 & TR34/L98H \\
\hline 11-0104A & Cucurbit fields & $>16$ & 1 & 2 & 232 & 0.5 & 2 & TR34/L98H \\
\hline 11-0104B & Cucurbit fields & $>16$ & 1 & 2 & 132 & 0.5 & 2 & F46Y; M172V; N248T; D255E \\
\hline 11-0104D & Cucurbit fields & $>16$ & 1 & 2 & 132 & 1 & 1 & TR34/L98H \\
\hline $11-0317 C$ & Cucurbit fields & $>16$ & 2 & 2 & 132 & 0.5 & 0.5 & TR34/L98H \\
\hline 11-0317D & Cucurbit fields & $>16$ & 1 & 1 & 132 & 0.5 & 1 & TR34/L98H \\
\hline 11-0396 & Apple orchard & $>16$ & 2 & 2 & 132 & 0.5 & 1 & TR34/L98H \\
\hline
\end{tabular}

EUCAST: European Committee on Antimicrobial Susceptibility Testing; MIC: minimal inhibitory concentration.

Isolates with MIC of itraconazole and voriconazole $>2 \mathrm{mg} / \mathrm{L}$ and those with MIC of posaconazole $>0.25 \mathrm{mg} / \mathrm{L}$ by broth microdilution method according to EUCAST, were considered resistant [15-17]. Data obtained by EUCAST and Etest differed, however results in a +/- 2 dilution range are considered acceptable.

a The azoles used for susceptibility testing were ITZ (itraconazole), POS (posaconazole), VRC (voriconazole).

\section{FIGURE 2}

Alignment of three amino acid sequences derived from the Cyp51A genetic sequence from itraconazole susceptible and resistant isolates, Italy, May 2011-June 2012

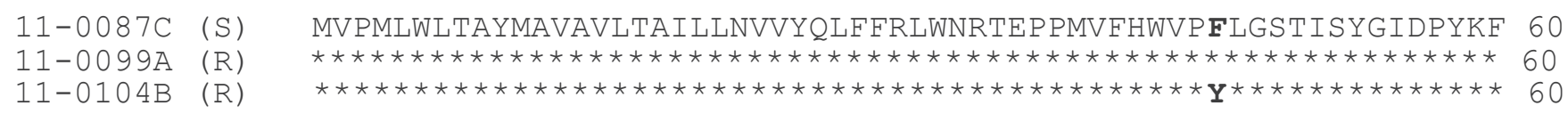

11-0087C (S) FFACREKYGDIFTFILLGQKTTVYLGVQGNEFILNGKLKDVNAEEVYSPLTTPVFGSDVV 120

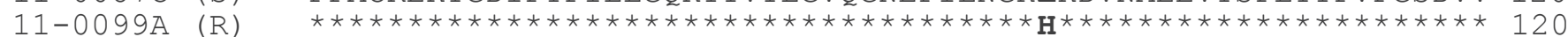

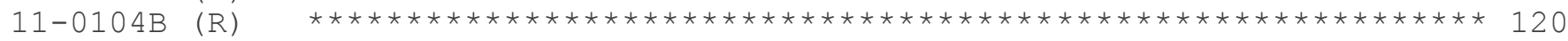

11-0087C (S) YDCPNSKLMEQKKFIKYGLTQSALESHVPLIEKEVLDYLRDSPNFQGSSGRDISAAMAE 180

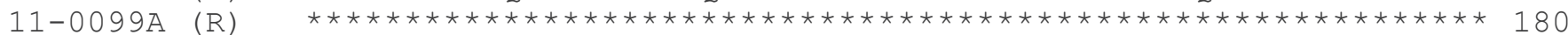

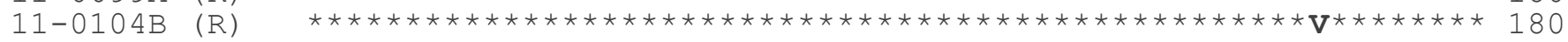

11-0087C (S) ITIFTAARALQGQEVRSKLTAEADLYHDLDKGFTPINFMLPWAPLPHNKKRDAAHARMR 240

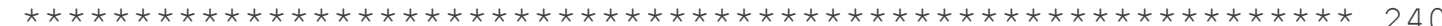

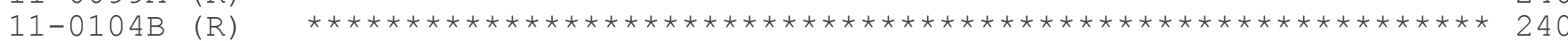

11-0087C (S) SIYVDIINQRRLDGDKDSQKSDMIWNLMNCTYKNGQQVPDKEIAHMMITLLMAGQHSSSS 300

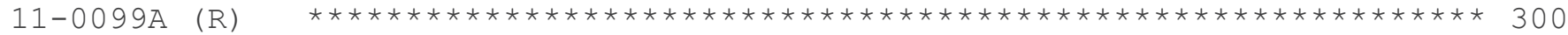

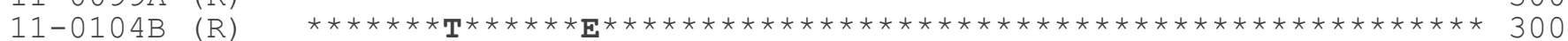

11-0087C (S) ISAWIMLRLASQPKVLEELYQEQLANLGPAGPDGSLPPLQYKDLDKLPFHQHVIRETLRI 360

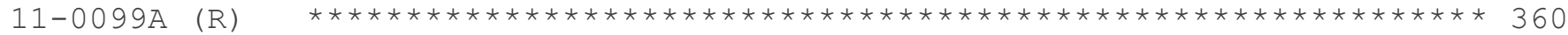

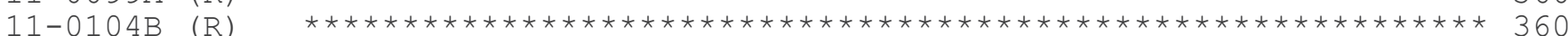

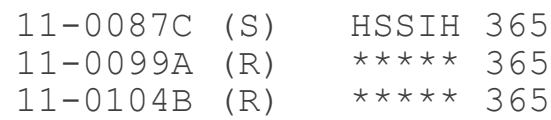

An asterisk $\left(^{*}\right)$ indicates that the amino acid in the sequence is identical to that of the sequence presented at the top of the alignment. The sequence $11-0087 \mathrm{C}$ is derived from an itraconazole susceptible (S) isolate, while the sequences 11-0099A, with the resulting L98 mutation, and 11-0104B, with other resulting amino acid substitutions, are from respective itraconazole resistant (R) isolates. 
Allelic profiles at six microsatellite loci of itraconazole resistant $(n=8)$ and susceptible $(n=5)$ environmental isolates, Italy, May 2011-June 2012

\begin{tabular}{|c|c|c|c|c|c|c|c|}
\hline \multirow{2}{*}{ Isolate } & \multirow{2}{*}{$\mathrm{R} / \mathrm{S}$} & \multicolumn{6}{|c|}{ Fragment size as bp (number of repeats) } \\
\hline & & STRAf3A & STRAf3B $_{3}$ & $\mathrm{STRAf}_{3} \mathrm{C}$ & $\mathrm{STRAf}_{4} \mathrm{~A}$ & $\mathrm{STRAf}_{4} \mathrm{~B}$ & STRAf $_{4} \mathrm{C}$ \\
\hline 11-0087A & $\mathrm{R}$ & $292(60)$ & $164(10)$ & $78(5)$ & $182(9)$ & $185(9)$ & $185(10)$ \\
\hline 11-0099A & $\mathrm{R}$ & $310(66)$ & $158(8)$ & $78(5)$ & $179(8)$ & $185(9)$ & $185(10)$ \\
\hline 11-0104A & $\mathrm{R}$ & $323(70)$ & $158(8)$ & $86(8)$ & $179(8)$ & 185 (9) & $175(7)$ \\
\hline $11-0104 B$ & $\mathrm{R}$ & $161(18)$ & 162 (9) & 108 (15) & 201 (13) & 184 (9) & $175(7)$ \\
\hline 11-0104D & $\mathrm{R}$ & $179(23)$ & $160(9)$ & $78(5)$ & $183(9)$ & 184 (9) & $185(10)$ \\
\hline $11-0317 C$ & $\mathrm{R}$ & $203(31)$ & $164(10)$ & $75(4)$ & $186(10)$ & $180(8)$ & $224(20)$ \\
\hline $11-0396$ & $\mathrm{R}$ & $310(66)$ & $158(8)$ & $80(6)$ & $178(8)$ & 184 (9) & $185(10)$ \\
\hline 11-0023B & $\mathrm{S}$ & $212(34)$ & $164(10)$ & $194(42)$ & $196(12)$ & 184 (9) & $175(7)$ \\
\hline $11-0034 \mathrm{~A}$ & $\mathrm{~S}$ & $212(34)$ & $156(7)$ & $80(6)$ & $182(9)$ & $180(8)$ & $242(26)$ \\
\hline $11-0036 C$ & $S$ & $222(37)$ & $164(10)$ & $80(6)$ & $196(12)$ & $175(7)$ & $162(5)$ \\
\hline $11-0104 \mathrm{E}$ & $\mathrm{S}$ & $219(36)$ & 169 (12) & $80(6)$ & $185(10)$ & $192(11)$ & 181 (9) \\
\hline
\end{tabular}

R: itraconazole resistant; S: itraconazole susceptible.

The nine itraconazole- and posaconazole-resistant isolates were recovered from pot composts ( 2 isolates from 2 different rose pots from Genoa), from apple orchard ( 1 isolate from an apple orchard near the northern border of Italy), and from cucurbit fields (6 isolates). These last six isolates were from three different samples, 11-0099, 11-0104 and 11-0317, collected in different fields and/or dates.

All nine resistant isolates were identified as $A$. fumigatus sensu stricto by amplification of a fraction of the beta-tubulin gene.

Sequence analysis of cyp51A gene showed the t364a point mutation, which results in the $\mathrm{L} 98 \mathrm{H}$ substitution, combined with the 34 -bp tandem repeat in the promoter region, in seven of nine itraconazole- and posaconazole-resistant isolates (Table 2). The $\mathrm{TR}_{34} /$ $\mathrm{L} 98 \mathrm{H}$ alteration was neither detected in the four azole susceptible isolates used as control nor in the resistant isolates $11-0088 \mathrm{E}$ and $11-0104 \mathrm{~B}$. No mutation in the cyp51A gene was found in the recovered sequence of 11-0088E. The other resistant isolate (11-0104B) lacking the mutation leading to the $\mathrm{L} 98 \mathrm{H}$ substitution had four other inferred amino acid changes at codons 46 , 172, 248 and 255, as reported in Figure 2.

Eight of nine resistant isolates (one was no more vital) and five additional susceptible environmental isolates were genotyped by microsatellite analysis. The results showed that all the isolates presented genotypes different from each other (Table 3).

\section{Discussion}

Acquired resistance to azoles develops in response to exposure of fungi to azole compounds in patients and in agricultural settings and is favoured by long duration of exposure to these compounds and high numbers of reproducing fungi $[1,19,20]$. Acquisition of resistance in patients is characterised by a variety of resistance mechanisms. The dominance of the $\mathrm{TR}_{34} / \mathrm{Lg8H}$ resistance mechanism in unrelated clinical isolates in a large Dutch culture collection suggested that isolates with this mechanism might be present in the environment, favoured by azole fungicides used in agriculture [20]. The detection of the $\mathrm{TR}_{34} / \mathrm{Lg} 8 \mathrm{H}$ resistance mechanism also in Italy, in four $A$. fumigatus isolates from two azole-naïve patients among the 209 isolates tested in the SCARE project [13] and in an additional isolate from an azole-exposed patient, lead to investigate the presence of azole-resistant $A$. fumigatus in the environment in our country.

Nine of the 58 isolates obtained by screening soil samples collected in northern Italy on an itraconazole containing medium were confirmed to be resistant to itraconazole and posaconazole by MIC determined with broth microdilution and Etest. Seven of these nine had also a reduced susceptibility to voriconazole when tested with broth microdilution. The discrepancy between the numbers of isolates on the screening medium containing itraconazole at a concentration of 4 $\mathrm{mg} / \mathrm{L}$ and the numbers of confirmed resistant isolates could be attributed to trailing of organic compounds present in the soil. 
Azole-resistant $A$. fumigatus sensu stricto were detected in $13 \%(6 / 47)$ of the soil samples collected and in $21 \%(6 / 29)$ of the soil samples confirmed as containing $A$. fumigatus. These results are in agreement with the data from other European countries: resistant isolates were detected in $8 \%$ of soil samples and in $11 \%$ of samples containing $A$. fumigatus in Denmark [8] and in $20.4 \%$ of $A$. fumigatus positive soil samples in the Netherlands [12]. Due to the limited number of samples it was impossibile to note a seasonal variation

Molecular analysis showed the presence of the $\mathrm{TR}_{34} /$ $\mathrm{L} 98 \mathrm{H}$ resistance mechanism in seven of nine resistant isolates. This resistance mechanism has also been reported in clinical isolates from several European and Asian countries $[1,7,9,13,21-25]$. To explain the prevalence of this resistance mechanism it was hypothesised that $\mathrm{TR}_{34} / \mathrm{Lg8H}$ isolates may have an advantage with respect to fitness compared to isolates with other mutations [6]. Other point mutations (in codons 46 , $172,248,255)$ were detected in one of the remaining resistant isolate. These mutations have been reported by other authors, and were found in both azole-susceptible and resistant strains $[7,26,27]$. No mutation was observed in the sequenced cyp51A gene of the other resistant isolate. These two resistant isolates would suggest the existence of other mechanisms of resistance.

As shown by molecular typing, all the resistant isolates were characterised as different strains confirming that resistance does not arise by a clonal expansion of a mutant but it is likely induced by the selective pressure resulting from the presence of azoles in the environment.

In conclusion this study provides evidence that azoleresistant $A$. fumigatus are detected in the environment also in Italy, in soil or composts exposed to azole fungicides, and confirms the presence of the $\mathrm{TR}_{34} / \mathrm{Lg} 8 \mathrm{H}$ mutation in several countries in Europe. Susceptibility testing of filamentous fungi is not routinely carried out in most medical microbiology laboratories, however the risk for patients to acquire multi-azole-resistant strains from the environment could have a serious impact on the management of life-threatening invasive infections. Finally, the possible selection of resistant fungal pathogens should lead applying azoles in agriculture with caution.
Acknowledgments

We thank prof. Annamaria Vercesi for providing information about the use of azoles in agriculture. A. Prigitano received a research grant "Dote ricerca”: FSE, Regione Lombardia.

Conflict of interest

None declared.

Authors' contributions

Prigitano Anna, Venier Valentina, Cogliati Massimo, Esposto Maria Carmela contributed to the planning of the research, performed sampling and laboratory tests, and contributed to the manuscript preparation. De Lorenzis Gabriella contributed to microsatellite analysis tests and contributed to the manuscript preparation. Tortorano Anna Maria planned the reaserch and prepared the manuscript.

\section{References}

1. European Centre for Disease Prevention and Control (ECDC). Technical Report. Risk assessment on the impact of environmental usage of triazoles on the development and spread of resistance to medical triazoles in Aspergillus species. Stockholm: ECDC;2013.

2. Prentice AG, Glasmacher A, Hobson RP, Schey S, Barnes RA, Donnelly JP, et al. Guidelines on the management of invasive fungal infection during therapy for haematological malignancy. London: British Committee for Standards in Haematology; 2010.

3. Walsh TJ, Anaissie EJ, Denning DW, Herbrecht R, Kontoyiannis DP, Marr KA, et al. Treatment of aspergillosis: clinical practice guidelines of the Infectious Diseases Society of America. Clin Infect Dis. 2008;46(3):327-60. http://dx.doi.org/10.1086/525258

4. Grossi PA, Gasperina DD, Barchiesi F, Biancofiore G, Carafiello G, De Gasperi A, et al. Italian guidelines for diagnosis, prevention, and treatment of invasive fungal infections in solid organ transplant recipients. Transplant Proc. 2011;43(6):246371.

http://dx.doi.org/10.1016/j.transproceed.2011.06.020

5. Herbrecht R, Flückiger U, Gachot B, Ribaud P, Thiebaut A, Cordonnier C. Antifungal Therapy in Leukemia Patients. UPDATE ECIL 4: Fourth European Conference on Infections in Leukaemia (ECIL-4); 2011 Sep 8-10; Juan-Les-Pins, France.

6. Verweij PE, Snelders E, Kema GH Mellado E, Melchers WJ. Azole resistance in Aspergillus fumigatus: a sideeffect of environmental fungicide use? Lancet Infect Dis. 2009;9(12):789-95.

http://dx.doi.org/10.1016/S1473-3099(09)70265-8

7. Howard SJ, Cerar D, Anderson MJ, Albarrag A, Fisher MC, Pasqualotto AC, et al. Frequency and evolution of azole resistance in Aspergillus fumigatus associated with treatment failure. Emerg Infect Dis. 2009:15(7):1068-76. http://dx.doi.org/10.3201/eid1507.090043

8. Mortensen KL, Mellado E, Lass-Flörl C, Rodriguez-Tudela JL, Johansen H K, Arendrup MC. Environmental study of azole-resistant Aspergillus fumigatus and other Aspergilli in Austria, Denmark, and Spain. Antimicrob Agents Chemother. 2010;54(11):4545-9. http://dx.doi.org/10.1128/AAC.00692-10

9. Mellado E, Garcia-Effron G, Alcazar-Fuoli L, Melchers WJ, Verweij PE, Cuenca-Estrella M, et al. A new Aspergillus fumigatus resistance mechanism conferring in vitro crossresistance to azole antifungals involves a combination of cyp $51 \mathrm{~A}$ alterations. Antimicrob Agents Chemother. 2007:51(6):1897-904.

http://dx.doi.org/10.1128/AAC.01092-06

10. Mellado E, Diaz-Guerra TM, Cuenca-Estrella M, RodriguezTudela JL. Identification of two different 14-a sterol demethylase-related genes (cyp51A and cyp51B) in Aspergillus fumigates and other Aspergillus species. J Clin Microbiol. 2001;39(7):2431-8.

http://dx.doi.org/10.1128/JCM.39.7.2431-2438.2001

11. Diaz-Guerra TM, Mellado E, Cuenca-Estrella M, RodriguezTudela JL.A point mutation in the 14 -a sterol demethylase gene cyp $51 \mathrm{~A}$ contributes to itraconazole resistance in Aspergillus 
fumigatus. Antimicrob Agents Chemother. 2003;47(3):1120-24. http://dx.doi.org/10.1128/AAC.47.3.1120-1124.2003

12. Snelders E, Huis In't Veld RA, Rijs AJ, Kema GH, Melchers WJ, Verweij PE. Possible environmental origin of resistance of Aspergillus fumigatus to medical triazoles. Appl Environ Microbiol. 2009;75(12):4053-7. http://dx.doi.org/10.1128/AEM.00231-09

13. Van Der Linden JW, Arendrup MC, Verweij PE. Prospective international surveillance of azole resistance in Aspergillus fumigatus (Af) (SCARE-network). Abstract M 490 presented at: 51th ICAAC Interscience Conference on Antimicrobial Agents and Chemotherapy; 2011 Sep 17-20; Chicago, IL.

14. Rodriguez-Tudela JL, Arendrup MC, Arikan S, Barchiesi F, Bille J, Chryssanthou E, et al. EUCAST DEFINITIVE DOCUMENT E.DEF 9.1: Method for the determination of broth dilution minimum inhibitory concentrations of antifungal agents for conidia forming moulds. EUCAST E.DEF 9.1. 2008;1-13.

15. Arendrup MC, Cuenca-Estrella M, Lass-Flörl C, Hope WW; European Committee on Antimicrobial Susceptibility Testing Subcommittee on Antifungal Susceptibility Testing (EUCASTAFST). EUCAST technical note on Aspergillus and amphotericin $B$, itraconazole, and posaconazole. Clin Microbiol Infect. 2012;18(7):E248-50. http://dx.doi.org/10.1111/j.1469-0691.2012.03890.x

16. Verweij PE, Howard SJ, Melchers WJ, Denning DW. Azoleresistance in Aspergillus: proposed nomenclature and breakpoints. Drug Resist Updat. 2009;12(6):141-7. http://dx.doi.org/10.1016/j.drup.2009.09.002

17. Hope WW, Cuenca-Estrella M, Lass-Flörl C, Arendrup MC; European Committee on Antimicrobial Susceptibility TestingSubcommittee on Antifungal Susceptibility Testing (EUCASTAFST). EUCAST Technical Note on Voriconazole and Aspergillus spp. Clin Microbiol Infect. 2013;19(6):E278-80. http://dx.doi.org/10.1111/1469-0691.12148

18. de Valk HA, Meis JF, Curfs IM, Muehlethaler K, Mouton JW, Klaassen $\mathrm{CH}$. Use of a novel panel of nine short tandem repeats for exact and high-resolution fingerprinting of Aspergillus fumigatus isolates. J Clin Microbiol. 2005;43(8):4112-20. http://dx.doi.org/10.1128/JCM.43.8.4112-4120.2005

19. Anderson JB. Evolution of antifungal-drug resistance: mechanisms and pathogen fitness. Nat Rev Microbiol. 2005;3(7):547-56. http://dx.doi.org/10.1038/nrmicro1179

20. Hof H. Critical annotations to the use of azole antifungals for plant protection. Antimicrob Agents Chemother. 2001;45 (11):2987-90. http://dx.doi.org/10.1128/AAC.45.11.2987-2990.2001

21. Snelders E, Van der Lee HA, Kuijpers J, Rijs AJ, Varga J, Samson $\mathrm{RA}$, et al. Emergence of azole resistance in Aspergillus fumigatus and spread of a single resistance mechanism. PLoS Med. 2008;5(11):e219.

http://dx.doi.org/10.1371/journal.pmed.0050219

22. Howard SJ, Pasqualotto AC, Denning DW. Azole resistance in allergic bronchopulmonary aspergillosis and Aspergillus bronchitis. Clin Microbiol Infect 2010;16(6):683-8. http://dx.doi.org/10.1111/j.1469-0691.2009.02911.x

23. Jeurissen A, Cooreman S, Van Kerckhoven W, Van Leemput J, Vanhove P, Lagrou K, et al. Invasive pulmonary aspergillosis due to a multi-azole resistant Aspergillus fumigatus. Acta Clinica Belgica 2012;67(1):46-8 http://dx.doi.org/10.1179/ACB.67.1.2062627

24. Hamprecht A, Buchheidt D, Vehreschild JJ, Cornely OA, Spiess $B$, Plum G, et al. Azole-resistant invasive aspergillosis in a patient with acute myeloid leukaemia in Germany. Euro Surveillance 2012;17(36):20262.

25. Rath PM, Buchheidt D, Spiess B, Arfanis E, Buer J, Steinmann J. First reported case of azole-resistant Aspergillus fumigates due to the TR/L98H mutation in Germany. Antimicrob Agents Chemother 2012;56(11):6060-61. http://dx.doi.org/10.1128/AAC.01017-12

26. Rodriguez-Tudela JL, Alcazar-Fuoli L, Mellado E, AlastrueyIzquierdo A, Monzon A, Cuenca-Estrella M. Epidemiological cutoffs and cross-resistance to azole drugs in Aspergillus fumigatus. Antimicrob Agents Chemother 2008, 52(7): 246872. http://dx.doi.org/10.1128/AAC.00156-08

27. Snelders E, Karawajczyk A, Schaftenaar G, Verweij PE, Melchers WJ. Azole resistance profile of amino acid changes in Aspergillus fumigatus CYP $51 \mathrm{~A}$ based on protein homology modeling. Antimicrob Agents Chemother. 2010, 54(6):2425-30. http://dx.doi.org/10.1128/AAC.01599-09 